\title{
A Comparison of Electrochemical Performance of Carbon Aerogels with Adsorption Metal Ions for Super Capacitors
}

\author{
Xiaoxi Dong ${ }^{1,2,3, \dagger}$, Yuelong $\mathrm{Xu}^{2,3, \dagger}$, Shasha Wang ${ }^{1,2,3}$, Junping Zhao ${ }^{2,3}$, Bin Ren ${ }^{2,3}$, \\ Lihui Zhang ${ }^{2,3}$ and Zhenfa Liu 1,2,3,*D \\ 1 School of Chemical Engineering and Technology, Hebei University of Technology, Tianjin 300000, China; \\ a13292005986@126.com (X.D.); wssnys@126.com (S.W.) \\ 2 Institute of Energy Resources, Hebei Academy of Sciences, Shijiazhuang 050081, China; \\ xudalong.cool@163.com (Y.X.); zjp39698@126.com (J.Z.); renbints@163.com (B.R.); zlhkxy@126.com (L.Z.) \\ 3 Hebei Engineering Research Center for Water Saving in Industry, Shijiazhuang 050081, China \\ * Correspondence: liuzhenfa@hebut.edu.cn \\ + These authors contributed equally to this work.
}

Received: 30 September 2018; Accepted: 8 November 2018; Published: 14 November 2018

\begin{abstract}
Environmental problems caused by metal ions have caused widespread concern in recent years. In this work, carbon aerogels (CAs) adsorbing different metal ions were prepared. The adsorption performance and kinetics of metal ions $(\mathrm{Cu}(\mathrm{II}), \mathrm{Cr}(\mathrm{VI})$, and $\mathrm{Fe}(\mathrm{III}))$ on carbon aerogels were systematically investigated. The results indicated that the maximum adsorption capacity of $\mathrm{Cu}$ (II) was $424 \mathrm{mg} \cdot \mathrm{g}^{-1}$ in $600 \mathrm{mg} \cdot \mathrm{L}^{-1}$ copper solution. Adsorption performances of $\mathrm{Cu}$ (II), $\mathrm{Cr}(\mathrm{VI})$, and $\mathrm{Fe}(\mathrm{IIII})$ on CAs well fitted with a pseudo-second-order kinetic model. The structures and morphologies of metal-containing samples were characterized by scanning electron micrographs (SEM), Energy Dispersive Spectrometer (EDS), transmission electron microscope (TEM), and X-ray diffraction (XRD). The results demonstrated that the texture and electrochemical performance of CAs adsorbing metal ions exhibited a clear change. The specific surface area of CAs for adsorbing copper ions was $450 \mathrm{~m}^{2} \cdot \mathrm{g}^{-1}$ and they showed a small average pore diameter $(7.16 \mathrm{~nm})$. Furthermore, CAs adsorbing metals could be used for the super capacitor. The specific capacitance of CAs adsorbing copper ions could reach $255 \mathrm{~F} \cdot \mathrm{g}^{-1}$ at a current density of $1.0 \mathrm{~A} \cdot \mathrm{g}^{-1}$. The CA-Cu electrode materials exhibited excellent reversibility with a cycling efficiency of $97 \%$ after 5000 cycles.
\end{abstract}

Keywords: carbon aerogels; adsorption behavior; metal ions; super capacitor; electrochemical performance

\section{Introduction}

Water pollution and soil contamination from heavy metal ions, which resulted from various industrial manufacturing, had been a worldwide environmental problem. Therefore, the removal of heavy metal ions from wastewater and soil have attracted more and more attention in recent years. Traditional methods for removing heavy metal ions included adsorption, precipitation, flocculation, reverse osmosis, ion exchange, and electrochemical treatments [1-5]. Recently, adsorption has become an effective, economic, and easily operational method to control metal pollutants. Common adsorbents included carbon nanotubes, activated carbon, and carbon aerogels.

Pekala et al. [6] first discovered carbon aerogels in 1989. Carbon aerogels (CAs) had nanostructures, a high specific surface area, porosities, and high electric conductivities. These excellent characteristics made CAs broadly applicable in environmental treatments and some good results have been achieved by using these materials [7,8]. Kadirvelu et al. [9] studied CAs as adsorbents that adsorb metal ions 
in multi-component systems. The results revealed that they were competitive for the adsorptions of the three metal ions. The adsorption of each ion conformed to the Langmuir and Freundlich model. Kabbashi et al. [10] found that carbon nanotubes could adsorb lead ions to remove them from aqueous solutions. The results showed that the maximum adsorption capacity was $102.04 \mathrm{mg} \cdot \mathrm{g}^{-1}$ and the removal rate was $96.03 \%$. Li et al. [11] found the maximum adsorption capacity to be $55.25 \mathrm{mg} \cdot \mathrm{g}^{-1}$ for copper ions by CAs in aqueous solutions in the presence of a surfactant. Wang et al. [12] found that, due to the oxygen-containing functional groups of the acidified carbon nanotubes that were treated by concentrated nitric acid, the nanotubes could mainly adsorb $\mathrm{Pb}(\mathrm{II})$ through the formation of chemical complexes. The oxygen-containing functional groups accounted for $75.3 \%$ of all the $\mathrm{Pb}$ (II) adsorption capacity. These examples clearly demonstrated that carbon materials were widely used in wastewater treatment due to their low production cost and ability to remove a significant fraction of the heavy metal ions. However, some adsorbent adsorbing heavy metal ions had to be thrown away and this led to secondary pollution due to a lack of a proper treatment method. In this work, the CAs could be recycled and used for super capacitors after adsorbing heavy metals.

The super capacitors have been widely used and studied because of their advantages such as long service life and high power density $[13,14]$. CAs as electrode materials could be used for super capacitors due to a high specific surface area and electric conductivity. After the CAs adsorbed the metal ions, we could use the modified materials for super capacitors. Wang et al. [15] discovered that hybrid electrode material of carbon fiber and vanadium nitride (CF@VN) was prepared by adsorbing scrap metal ions at $800{ }^{\circ} \mathrm{C}$ under a mixed atmosphere of $\mathrm{NH}_{3}$ and $\mathrm{N}_{2}$. The results showed that the specific capacitance of the CF@VN material was $104.05 \mathrm{~F} \cdot \mathrm{g}^{-1}$ at the current density of $0.5 \mathrm{~A} \cdot \mathrm{g}^{-1}$. Hao et al. [16] used chitosan coated oxygen-containing functional carbon nanotubes to remove toxic metal ions and carbonized the mixing materials. Electrochemical measurements showed that the specific capacitance of $\mathrm{Cu}$-loaded and $\mathrm{Cr} \mathrm{N}$-loaded carbon composites was 144.9 and $114.9 \mathrm{~F} \cdot \mathrm{g}^{-1}$ at $2 \mathrm{mV} \cdot \mathrm{s}^{-1}$, respectively. Yu et al. [17] reduced graphene oxide-coated cellulose fiber (rGO@CF) as adsorbent in which methylene blue (MB), alizarin red S (ARS), and indigo carmine (IC) were quickly and easily adsorbed and removed from the aqueous solution and then loaded on rGO@CF paper. The flexible supercapacitors/rGO@CF electrode exhibited excellent electrochemical performances.

In this case, carbon aerogels were used to adsorb $\mathrm{Cu}(\mathrm{II}), \mathrm{Cr}(\mathrm{VI})$, and $\mathrm{Fe}(\mathrm{III})$. The adsorption isotherms were suitable for the Langmuir model. In addition, metal-adsorbed carbon aerogels could be used as super capacitor materials. By observing electrochemical measurements, the specific capacitance of carbon aerogels adsorbing copper ions could reach $255 \mathrm{~F} \cdot \mathrm{g}^{-1}$ at $1.0 \mathrm{~A} \cdot \mathrm{g}^{-1}$. Carbon aerogels as adsorbent provided a new way to remove metal ions. The corresponding materials exhibited an excellent electrochemical performance and could be used as super capacitor electrode materials and resource utilization.

\section{Materials and Methods}

\subsection{Preparation of the Carbon Aerogels}

Phloroglucinol $(\mathrm{P})$, resorcinol $(\mathrm{R})$, and formaldehyde $(\mathrm{F})$ were used as raw materials to prepare the carbon aerogels. The molar ratio of $\mathrm{P} / \mathrm{R}$ was 0.14 . In addition, sodium carbonate $(\mathrm{C})$ and ascorbic acid $(\mathrm{Vc})$ were used as catalysts. The ratios of $\mathrm{C} /(\mathrm{P}+\mathrm{R})$ and $\mathrm{V}_{\mathrm{c}} /(\mathrm{P}+\mathrm{R})$ were 0.002 and 0.02 , respectively. The mass concentration of the distilled water $(\mathrm{P}+\mathrm{R}+\mathrm{F}+\mathrm{C}+\mathrm{Vc})$ in the solution was $45 \%$. All of the solutions of raw materials were prepared in distilled water and stored in glass bottles. Afterward, the glass bottles were placed into an ultrasonic bath to obtain uniform solutions. The bottles were left in the water bath at $60^{\circ} \mathrm{C}$ for 2 days, which generated gels. The wet gels were placed in acetone for 3 days and the solvent was replaced every day. The gel was placed in a tube furnace, evacuated, and then purged with nitrogen. Afterward, the gels were carbonized by a temperature programming method. The temperature of the carbonation process was set so that uniform holes would form. Lastly, the CAs were obtained. 


\subsubsection{Determination of the Metal Ions}

$\mathrm{Fe}(\mathrm{II})$ was determined by spectrophotometry. A total of $4.21 \mathrm{~g}\left(\mathrm{NH}_{4}\right)_{2} \mathrm{Fe}\left(\mathrm{SO}_{4}\right) \cdot 6 \mathrm{H}_{2} \mathrm{O}$ was dissolved in distilled water to prepare a standard iron solution. The standard iron solution $\left(50 \mathrm{~mL}, 600 \mathrm{mg} \cdot \mathrm{L}^{-1}\right)$ and $5 \mathrm{mg}$ of CAs were added to a beaker and stirred on a magnetic stirrer for $1 \mathrm{~h}, 2 \mathrm{~h}, 3 \mathrm{~h}, 5 \mathrm{~h}, 7 \mathrm{~h}$, $9 \mathrm{~h}, 11 \mathrm{~h}$, and $18 \mathrm{~h}$. The stirred solution was centrifuged, $20 \mathrm{~mL}$ of the supernatant was transferred to a $100 \mathrm{~mL}$ volumetric flask, and then it was diluted with water to the mark. The absorbance was measured at its maximum absorption wavelength $(230 \mathrm{~nm})$ and the concentration of Fe(II) versus absorbance was plotted [18]. Distilled water was used as a reference during the entire operation. The method for measuring the concentration of $\mathrm{Cr}$ (VI) $\left(2.27 \mathrm{~g} \mathrm{~K}_{2} \mathrm{CrO}_{4}\right)$ was almost the same as that of $\mathrm{Fe}(\mathrm{III})$. However, $\mathrm{Cr}$ (VI) was measured at a maximum absorption wavelength of $370 \mathrm{~nm}$ [19]. When measuring the concentration of $\mathrm{Cu}$ (II) $\left(3.39 \mathrm{~g} \mathrm{Cu}\left(\mathrm{NO}_{3}\right)_{2} \cdot 3 \mathrm{H}_{2} \mathrm{O}\right)$, the copper reagent, which served as the color developing agent was added, and the $\mathrm{pH}$ was adjusted to 9 with ammonia $(13 \mathrm{~mol} / \mathrm{L})$. The concentration was determined at the maximum absorption wavelength $(452 \mathrm{~nm})$ [20].

\subsubsection{Preparation of Metallic CA Electrodes}

The CA powder $(3 \mathrm{~g})$ was mixed with $200 \mathrm{~mL}$ of iron solution, chromium solution, and copper solution (600 mg. $\mathrm{L}^{-1}$, respectively) and the mixtures were stirred for $24 \mathrm{~h}$ so that the metal ions were fully adsorbed and then the samples were dried in an oven at $45^{\circ} \mathrm{C}$. Lastly, the samples were carbonized at $600{ }^{\circ} \mathrm{C}$. The CAs alone were used as the contrast. We named the carbonized samples as CA-Fe, CA-Cr, CA-Cu, and blank, respectively, and they were denoted CA-X and the blank. Additionally, the CAs adsorbing copper ions that were not carbonized were denoted CA-Cu-0. After carbonization, all the samples were ball milled for $6 \mathrm{~h}$ and then passed through a 200 mesh sieve. The samples were then added to polytetrafluoroethylene (PTFE) at a mass ratio of 95:5. Approximately $40 \mathrm{~mL}$ of deionized water was added and the mixtures were stirred for $6 \mathrm{~h}$ and dried in a drying oven at $105{ }^{\circ} \mathrm{C}$ overnight. Lastly, the dried substances were placed on foam nickel. The electrodes were prepared by using a tablet press with $10 \mathrm{MPa}$. Then the samples were dried and weighed. To test the electrochemical performance, the samples were soaked in $6 \mathrm{M} \mathrm{KOH}$ electrolyte for $24 \mathrm{~h}$.

\subsection{Carbon Aerogel Adsorption Kinetics}

The kinetics of the CAs adsorption processes were studied. The appropriate kinetic model was selected to fit the adsorption process. The relevant adsorption kinetic parameters were calculated, which was important for investigating the adsorption processes. In this experiment, pseudo-first-order kinetic equations and pseudo-second-order kinetic equations were used to fit the adsorption process and experimental data of the CAs with metal ions. The expression for the pseudo-first-order kinetic equation is shown below [21].

$$
\ln \left(Q_{e}-Q_{t}\right)=\ln Q_{e}-\frac{k_{1}}{2.303} \mathrm{t}
$$

The expression for the pseudo-second-order kinetic equation is shown below.

$$
\frac{\mathrm{t}}{Q_{t}}=\frac{1}{k_{2} Q_{e}^{2}}+\frac{\mathrm{t}}{Q_{e}}
$$

In the equation, $k_{1}\left(\mathrm{~min}^{-1}\right)$ and $k_{2}\left(\mathrm{~g} \cdot(\mathrm{mg} \cdot \mathrm{min})^{-1}\right)$ stood for the rate constants of pseudo-first-order and pseudo-second-order adsorption, respectively. $t$ was the reaction time ( $\mathrm{min}), Q_{t}$ was the amount of adsorption at time $t\left(\mathrm{mg} \cdot \mathrm{g}^{-1}\right)$, and $Q_{e}$ was the balanced adsorption capacity $\left(\mathrm{mg} \cdot \mathrm{g}^{-1}\right)$. In Equation (1), plotting $\ln \left(Q_{e}-Q_{t}\right)$ against $t$ linearizes the data. If a linear function was obtained, it could be used as a pseudo-first-order kinetic model. Similarly, in Equation (2), $\frac{\mathrm{t}}{\mathrm{Q}_{t}}$ plotted against $\mathrm{t}$ linearizes the data. If a linear function was obtained, it could be used as a pseudo-second-order kinetic model.

In 1918, Langmuir [22] proposed the theory of monolayer adsorption. It was believed that, when the gas molecules collided with the solid surface, the adsorption rate was equivalent to the rate 
that it desorbed from the solid surface, which corresponds to a dynamic equilibrium process. The basic mathematical expression of the Langmuir isotherm equation is shown below.

$$
\frac{C_{e}}{Q_{e}}=\frac{1}{Q_{m} b}+\frac{C_{e}}{Q_{m}}
$$

In this equation, $Q_{e}$ is the balanced adsorption capacity $\left(\mathrm{mg} \cdot \mathrm{g}^{-1}\right), Q_{m}$ is the monolayer saturated adsorption $\left(\mathrm{mg} \cdot \mathrm{g}^{-1}\right), \mathrm{b}$ is the adsorption equilibrium constant $\left(\mathrm{L} \cdot \mathrm{mg}^{-1}\right)$, and $\mathrm{C}_{\mathrm{e}}$ is the concentration of adsorbates in the system at the adsorption equilibrium $\left(\mathrm{mg} \cdot \mathrm{L}^{-1}\right)$.

In addition, the adsorption capacity of carbon aerogels could be assessed based on the amount of adsorbed metal $\left(Q_{e}\right)$. The amount of adsorbed metal was calculated by the following formula [21].

$$
q_{e}=\frac{C_{0}-C_{e}}{m} V
$$

In Formula (4), $q_{e}$ is the adsorption capacity $\left(\mathrm{mg} \cdot \mathrm{g}^{-1}\right), C_{0}$ and $C_{e}$ are the concentrations of metal ions in the solution before and after adsorption, respectively $\left(\mathrm{mg} \cdot \mathrm{L}^{-1}\right), \mathrm{m}$ is the quantity of adding adsorbent $(\mathrm{g})$, and $\mathrm{V}$ is the volume of the solution containing metal ions (L).

\subsection{Characterization}

The gels were carbonized by tube furnace (OTF-1200X-5L, HeFei Kejing Materials Technology Co. Ltd., Hefei, China) at $600{ }^{\circ} \mathrm{C}$. The Brunaure-Emmett-Teller method and Density-Functional-Theory (DFT) model calculated the specific surface area and the micropore surface area (ASAP 2420, Norcross, GA, USA). The pore volumes and pore size were used in the Barrett-Joyner-Halenda (BJH) model. The degassing temperature was maintained at $90{ }^{\circ} \mathrm{C}$ for $1 \mathrm{~h}$ and then increased to $250{ }^{\circ} \mathrm{C}$ for $6 \mathrm{~h}$. The carrier gas was $\mathrm{N}_{2}$. The surface morphologies of the samples were analyzed by SEM (s-4800-I, Tescan, Brno, Czech Republic), which were equipped with an APOLLO EDS immobilizing the sample with conduction glue. The internal morphology was observed by TEM (JEM-2100 Plus, JEOL. Co. Ltd., Tokyo, Japan), which the ground CA-X powder was placed in an absolute ethanol solution and the ultrasonic wave was evenly uniform and dropped into the micro-grid. XRD (X-ray diffraction, Cu target, $\lambda=1.54 \AA$ and $K \alpha$ radiation, UItima IV X-ray diffractometer, Rigaku, Tokyo, Japan) was used to identify the specific peak to metals and the peaks characteristic of the CAs. The surface compositions of CA-X were characterized by XPS (PHI5600, PHI, Lafayette, LA, USA). A UV-vis spectrophotometer (TU-1900, Beijing Persee Instruments Co. Ltd., Beijing, China) was used to measure the metal ions concentration and characterize the adsorption capacity of CAs. Electrochemical performances were measured with a GAMRY Interface 1000 electrochemical workstation. All the measurements used a three-electrode system with a saturated calomel electrode (SCE) and Pt as a reference and counter electrode. The CA-X and blank samples were the working electrode. In this work, cycle voltammetry $\left(\mathrm{CV}\right.$, scanning rate $0.1 \sim 20 \mathrm{mV} \cdot \mathrm{s}^{-1}$, scanning voltage -0.8 to $\left.0 \mathrm{~V}\right)$, electrochemical impedance spectroscopy (EIS), and charge and discharge testing (voltage range -0.8 to $0 \mathrm{~V}$, current density range 0.5 to $3.0 \mathrm{~A} \cdot \mathrm{g}^{-1}$ ) were used for the investigation. The formula to calculate the specific capacitance was shown below [23].

$$
C_{m}=2 \mathrm{I} \Delta \mathrm{t} /(m \Delta \mathrm{V})
$$

In this case, $C_{m}$ was the single-electrode specific capacitance $\left(\mathrm{F} \cdot \mathrm{g}^{-1}\right)$, I was the charge current (A), $\Delta \mathrm{t}$ was the charge time (s), $\mathrm{m}$ was the quality (g), and $\Delta \mathrm{V}$ was the potential window $(\mathrm{V})$. 


\section{Results and Discussion}

\subsection{Adsorption Kinetics of CA-X}

The results of the pseudo-first-order kinetic and the pseudo-second-order kinetic models under different stirring time were shown in Figure 1. From Figure 1A, in the pseudo-first-order kinetic model, the correlation coefficients $\left(\mathrm{R}^{2}\right)$ of CA-Fe, CA-Cr, and CA-Cu were 0.997, 0.946, and 0.915, respectively. In the pseudo-second-order kinetic model (Figure $1 \mathrm{~B}$ ), the $\mathrm{R}^{2}$ values of $\mathrm{CA}-\mathrm{Fe}, \mathrm{CA}-\mathrm{Cr}$, and $\mathrm{CA}-\mathrm{Cu}$ were $0.998,0.999$, and 0.992, respectively. Clearly, the pseudo-second-order kinetic model had a higher $\mathrm{R}^{2}\left(\mathrm{R}^{2}>0.99\right)$. The adsorbing metal ions followed pseudo-second-order kinetics model.
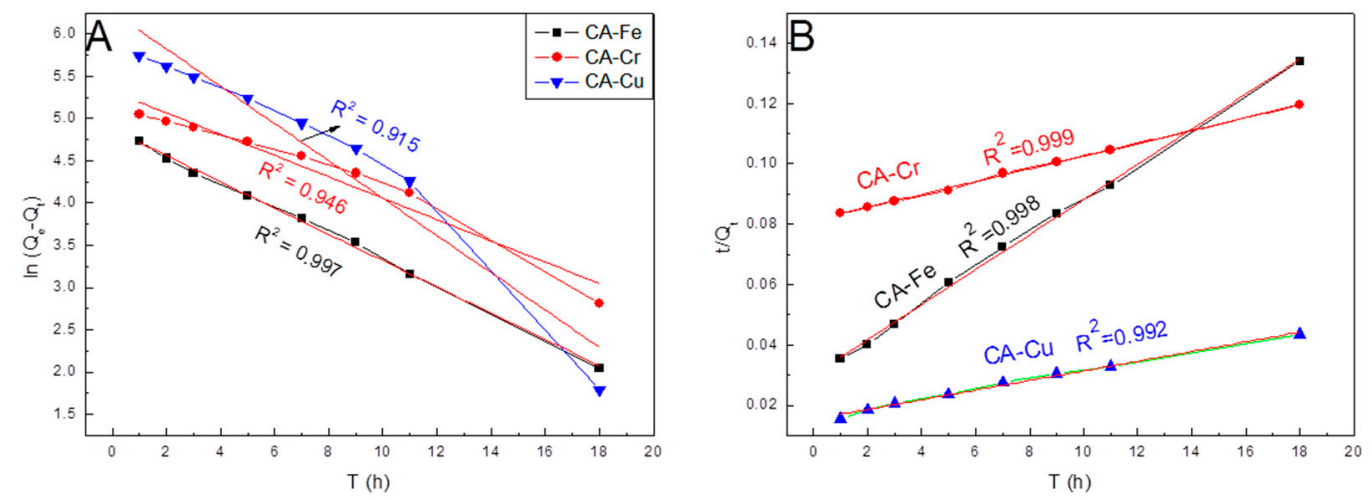

Figure 1. Figure 1. (A) Pseudo-first-order kinetic model and (B) pseudo-second-order kinetic model.

The results of fitting the Langmuir isothermal adsorption equation to the experimental data were shown in Figure 2. According to Figure 1, CA-Cu had the largest correlation coefficient $\left(\mathrm{R}^{2}=0.9999\right)$, which indicated that the adsorption process of $\mathrm{Cu}$ (II) on CAs was well fitted with physical adsorption. The adsorption capacities of carbon materials were largely dependent on the surface functional groups such as $-\mathrm{COOH}$ and $-\mathrm{C}=\mathrm{O}$, which could be introduced on the surface of the CAs. These functional groups mainly contributed to the adsorption of $\mathrm{Cu}$ (II) on the surface of the CAs [24]. Furthermore, the smaller ionic radius of $\mathrm{Cu}$ (II) was more beneficial for the adsorption on CAs [25]. Therefore, the experimental data were consistent with the Langmuir model of single-layer adsorption.

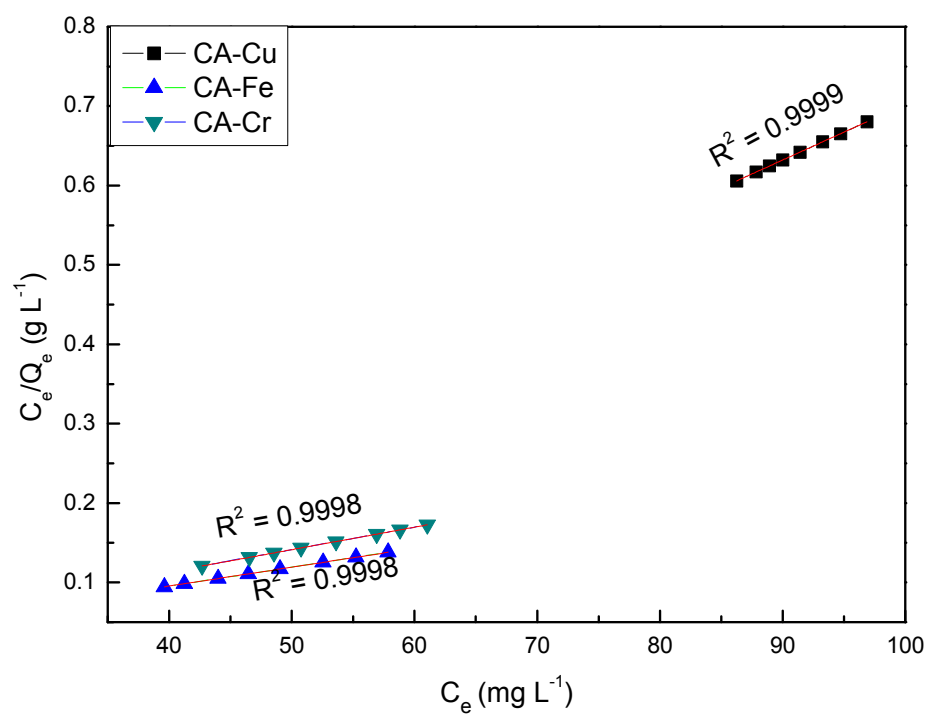

Figure 2. Langmuir isothermal adsorption model for CA-X.

Figure 3 showed the results of adsorption of metal ions by CAs. With increasing stirring time, the amounts of adsorbed metal by the CAs increased. In particularly, the maximum amount of Cu(II) 
adsorbed by the CAs was $424 \mathrm{mg} \cdot \mathrm{g}^{-1}$. As shown in Table 1 , the maximum adsorption amounts of $\mathrm{CA}-\mathrm{Fe}$ and CA-Cr were $133 \mathrm{mg} \cdot \mathrm{g}^{-1}$ and $139 \mathrm{mg} \cdot \mathrm{g}^{-1}$, respectively. The reason for this was the strong electrostatic attraction between the metal ions and the CAs [26]. Before UV measured the absorbance, the copper solution was adjusted to a $\mathrm{pH}$ of approximately 9 with ammonia. When the standard solution containing iron was prepared, $6 \mathrm{M} \mathrm{HNO}_{3}$ was added to dissolve the $\left(\mathrm{NH}_{4}\right)_{2} \mathrm{Fe}\left(\mathrm{SO}_{4}\right) \cdot 6 \mathrm{H}_{2} \mathrm{O}$ and the $\mathrm{pH}$ was approximately 6 . The $\mathrm{pH}$ value of the standard chromium solution was 7 by using $\mathrm{HNO}_{3}$ and $\mathrm{NaOH}$ to adjust. In acidic solutions, metal ions competed with $\mathrm{H}^{+}$for the adsorption sites, which resulted in the reduction of adsorption of the heavy metal ions. Therefore, Fe(III) had the smallest adsorption capacity $\left(133 \mathrm{mg} \cdot \mathrm{g}^{-1}\right)$ and the adsorption amount of $\mathrm{Cr}(\mathrm{VI})$ was $139 \mathrm{mg} \cdot \mathrm{g}^{-1}$. However, in an alkaline solution, the proportion of $(\mathrm{CuOH})^{+}$was large, the average charge density was small, and the electronegativity was high. At the same time, more anion adsorption sites provided by functional groups such as carboxyl and carbonyl and surface complexation with $\mathrm{Cu}$ (II) resulted in increasing adsorption [27]. The maximum adsorption capacity of different adsorbent for the removal metal ions was shown in Table 2.

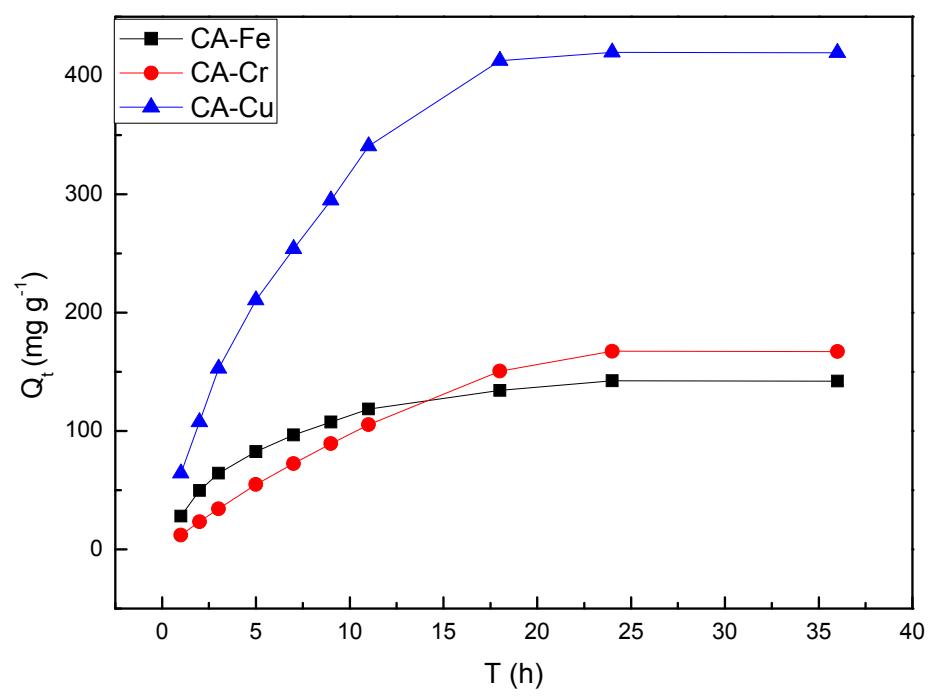

Figure 3. Adsorption isotherm of CA-X.

Table 1. The adsorption capacity of CA-X.

\begin{tabular}{|c|c|}
\hline Entry & Adsorption Capacity $\left(\mathrm{mg} \cdot \mathrm{g}^{-1}\right)$ \\
\hline CA-Fe & 133 \\
\hline CA-Cr & 139 \\
\hline $\mathrm{CA}-\mathrm{Cu}$ & 424 \\
\hline
\end{tabular}

Table 2. Comparative study of different adsorbent for the removal of metal ions.

\begin{tabular}{cccc}
\hline Adsorbents & Metal Ions & $\begin{array}{c}\text { Adsorption Capacities } \\
\left(\mathbf{m g} \cdot \mathbf{g}^{-\mathbf{1}} \mathbf{)}\right.\end{array}$ & Reference \\
\hline Active carbon & $\mathrm{Fe}$ & 166.7 & {$[28]$} \\
Carbon paper@Magnesium silicate & $\mathrm{Cu}$ & 113.5 & {$[29]$} \\
carbon nanotubes & $\mathrm{Cu}$ & 123.7 & {$[16]$} \\
Magnetic b-cyclodextrin/graphene oxide & $\mathrm{Cr}$ & 120.19 & {$[30]$} \\
Carbon bead-supported hollow carbon nanofibers & $\mathrm{Cr}$ & 51 & {$[31]$} \\
Carbon aerogel & $\mathrm{Cu} / \mathrm{Cr} / \mathrm{Fe}$ & $424 / 139 / 133$ & This work \\
\hline
\end{tabular}

\subsection{Pore structure of the $C A-X$}

The $\mathrm{N}_{2}$ adsorption-desorption isotherms of CA-Fe, CA-Cr, CA-Cu, and the blank at $77 \mathrm{~K}$ were shown in Figure 4. All the adsorption-desorption isotherms of $\mathrm{CA}-\mathrm{X}$ and blank were classified as type $\mathrm{IV}$, according to the IUPAC [32]. At lower relative pressures, the inflection points of CA-Fe, CA-Cr, 
and CA-Cu were gentler, which suggests less presence of micropores in CAs, which was caused by the metal ions adsorption on CAs [33,34]. When the relative pressure $\mathrm{P} / \mathrm{P}_{0}>0.8$, all the curves had an $\mathrm{H} 1$ type hysteresis loop, which indicated that there were mesopores and macropores in the materials and capillary condensation occurred.

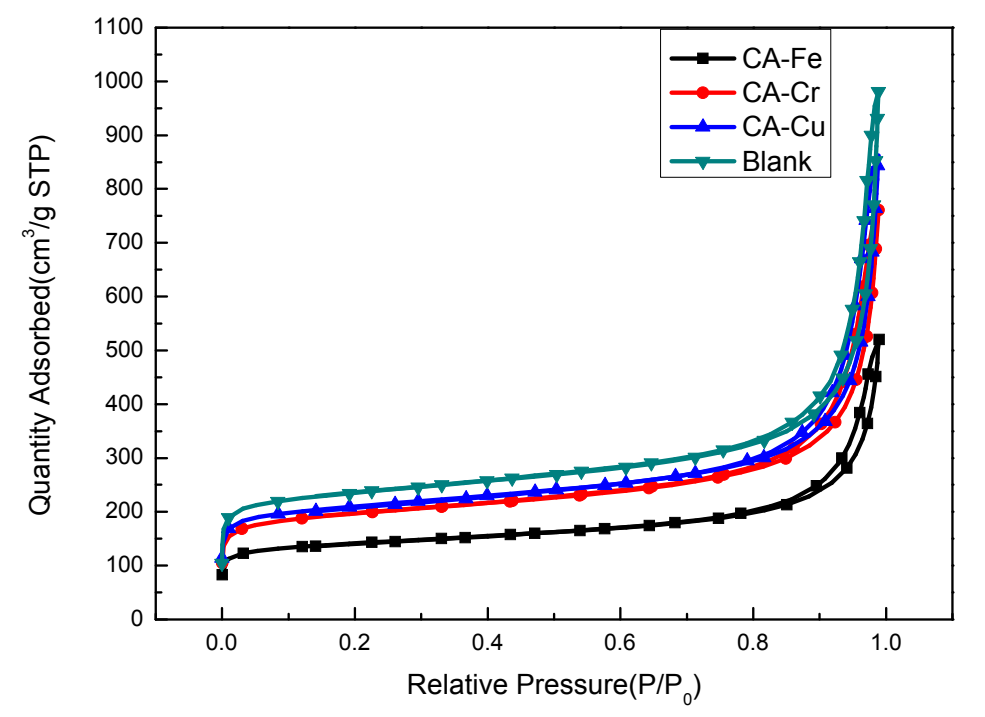

Figure 4. Nitrogen adsorption-desorption isotherms of the CA-X and the blank.

Figure 5 showed the pore size distribution. As shown in Figure 5, all curves showed typical hierarchical porosity and the materials were composed of micropores, mesopores, and macropores, which were advantageous for adsorbing metals. Adsorption occurred mainly in micropores while adsorption in micropores required mesoporous/macroporous transitions. From Figure 4, we could understand that the hysteresis loops of the samples were consistent with the H1 model in the IUPAC [32] regulations, which indicates that the materials had good channel connectivity.

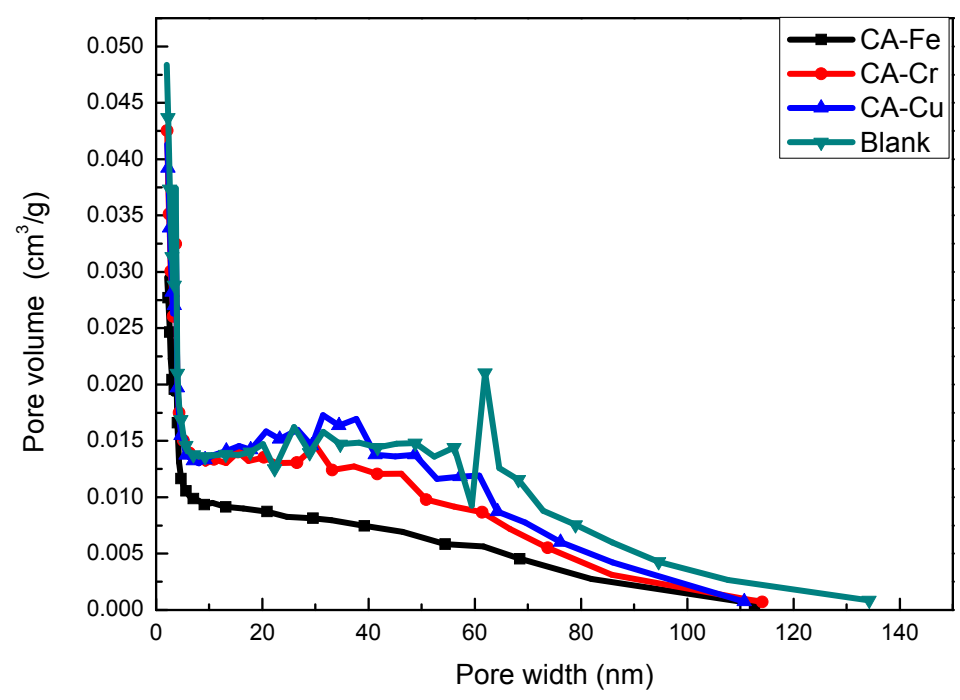

Figure 5. Pore size distribution in the CA-X samples and the blank.

Table 3 showed the specific surface area $\left(\mathrm{S}_{\mathrm{BET}}\right)$, total pore volume $\left(\mathrm{V}_{\text {total }}\right)$, micropore surface area $\left(\mathrm{S}_{\text {micro }}\right)$, and average pore diameter $\left(\mathrm{D}_{\text {average }}\right)$ of the $\mathrm{CA}-\mathrm{Fe}, \mathrm{CA}-\mathrm{Cr}, \mathrm{CA}-\mathrm{Cu}$, and blank samples. Clearly, the $C A-C u$ sample had the smallest $S_{B E T}, V_{\text {total }}, S_{\text {micro }}$, and $D_{\text {average values. The result was }}$ attributed to the occupation of adsorbing metal ions on CAs. As presented in Table 3, CA-Cu exhibited a lower specific surface area than other samples, which indicated that the percentage of micropores on 
carbon aerogels had a significant decrease. The blank sample exhibited a noticeable large pore volume than CA-X because the metal ions adsorption on CAs contributed to the decrease of the pore volume. The analysis result was in accordance with the $\mathrm{N}_{2}$ adsorption-desorption isotherms discussion. At the same time, the decreasing tendency of the specific surface area showed that the metal ions adsorption process was physical adsorption.

Table 3. Pore structure of the CA-X.

\begin{tabular}{ccccc}
\hline Entry & $\mathbf{S}_{\text {BET }}\left(\mathbf{m}^{\mathbf{2}} \cdot \mathbf{g}^{-\mathbf{1}}\right)$ & $\mathbf{S}_{\text {micro }}\left(\mathbf{m}^{\mathbf{2}} \cdot \mathbf{g}^{-\mathbf{1}}\right)$ & $\mathbf{D}_{\text {average }}(\mathbf{n m})$ & $\mathbf{V}_{\text {total }}\left(\mathbf{c m}^{\mathbf{3}} \cdot \mathbf{g}^{-\mathbf{1}}\right)$ \\
\hline CA-Fe & 666 & 413 & 8.00 & 1.33 \\
CA-Cr & 627 & 374 & 7.50 & 1.18 \\
CA-Cu & 450 & 274 & 7.16 & 0.81 \\
Blank & 695 & 463 & 8.11 & 1.52 \\
\hline
\end{tabular}

\subsection{SEM and TEM of CA-X}

Figure 6 presented the SEM images and EDS results of the morphologies of the samples. All samples had a nanostructure. Compared with that of the blank, the structures of CA-Fe, CA-Cr, and CA-Cu were more compact. As seen in Figure 6C, CA-Cu had a more dense porous structure, which was caused by more metal ion adsorption. The EDS was measured to identify the element. According to the Figure $6 \mathrm{G}$, we could confirm the CA-Fe, CA-Cr and CA-Cu had the existence of $\mathrm{Fe}, \mathrm{Cr}$, and $\mathrm{Cu}$, respectively. Figure 7 showed the TEM images of the $\mathrm{CA}-\mathrm{X}$ and blank. Figure $7 \mathrm{a}-\mathrm{C}$ showed a typical TEM image of the metallic oxide nanosphere, which indicated the appearance of $\mathrm{Fe}$, $\mathrm{Cr}$, and $\mathrm{Cu}$ in the Cas [35-37].

\subsection{XRD Patterns of $C A-X$}

Figure 8 showed the XRD patterns for the CA-Fe, CA-Cr, CA-Cu, and the blank materials. The CA-Cr, CA-Cu, and blank exhibited typical XRD peaks that could be indexed to (101) and (002), which showed that the CAs were composed of graphite carbon and amorphous carbon. However, CA-Fe did not have the (002) characteristic peak that might be due to the intensity of the iron oxide peaks and an increased average particle size. The loss of the active functional groups could decrease the adsorption capacity. The diffraction peaks located at $2 \theta=30.1^{\circ}, 35.8^{\circ}, 43.1^{\circ}$, and $53.8^{\circ}$ could be indexed to the (220), (311), (400), and (422) planes of $\mathrm{Fe}_{3} \mathrm{O}_{4}$, respectively [35]. The curve of CA-Cr could be indexed to (104) and (116), which were characteristic of $\mathrm{Cr}_{2} \mathrm{O}_{3}$ [38,39]. Regarding the sample of $\mathrm{CA}-\mathrm{Cu}$, the diffraction peaks at $38.9^{\circ}$ and $49.0^{\circ}$ matched the respective (110) and (111) planes of $\mathrm{CuO}$. In the above analysis, $\mathrm{Fe}, \mathrm{Cr}$, and $\mathrm{Cu}$ ions were absorbed into the $\mathrm{CAs}$.

\subsection{XPS Spectra of $C A-X$}

Figure $9 \mathrm{a}-\mathrm{c}$ showed the high-resolution XPS spectra of CA-Fe, CA-Cr, and CA-Cu, respectively. It was clear that in the $C A$ existed $C_{1 s}$ and $O_{1 s}$ from Figure 9 d,e. The $\mathrm{O}_{1 \mathrm{~s}}$ spectra possessed three peaks at $531 \mathrm{eV}(\mathrm{C}=\mathrm{O}), 533.3 \mathrm{eV}(\mathrm{C}-\mathrm{O}-\mathrm{C})$, and $532 \mathrm{eV}(\mathrm{COOH})$. The $\mathrm{C}_{1 \mathrm{~s}}$ spectrum could be fitted into six peaks at $284.6 \mathrm{eV}, 285.3 \mathrm{eV}, 287.4 \mathrm{eV}, 285.4 \mathrm{eV}, 289.05 \mathrm{eV}$, and $291.7 \mathrm{eV}$ corresponding to $\mathrm{SP}^{2}, \mathrm{SP}^{3}, \mathrm{C}=\mathrm{O}$, $\mathrm{C}-\mathrm{O}, \mathrm{O}-\mathrm{C}=\mathrm{O}$ and $\pi-\pi$, respectively $[40,41]$. It was known that these surface functional groups were favorable for metal adsorption because these functional groups can coordinate with metals to form coordinate bonds [42]. 

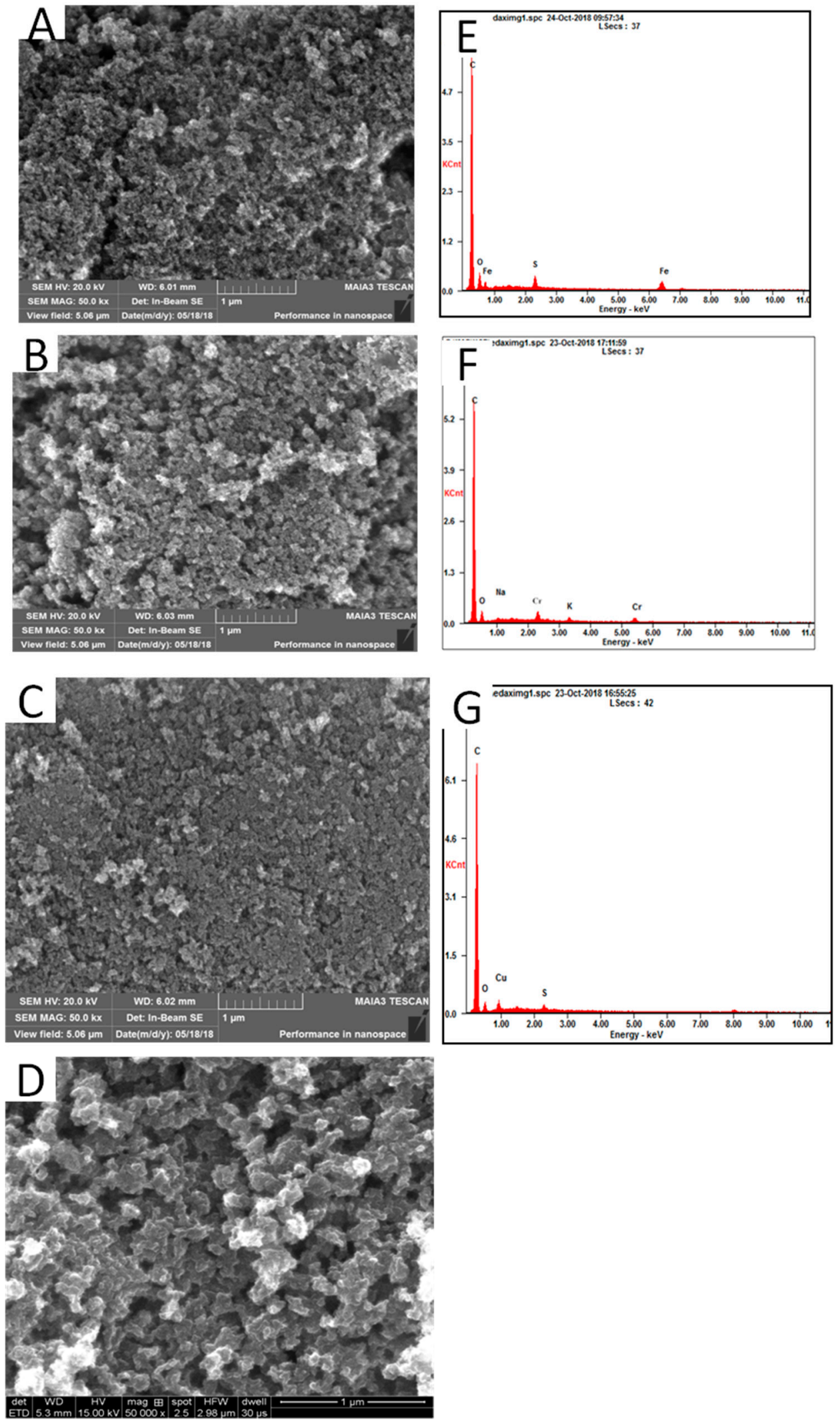

Figure 6. SEM images of CA-X (A) CA-Fe (B) CA-Cr (C) CA-Cu and (D) Blank, EDS of CA-X (E), $\mathrm{CA}-\mathrm{Fe}(\mathbf{F})$ and $\mathrm{CA}-\mathrm{Cr}(\mathbf{G})$. 

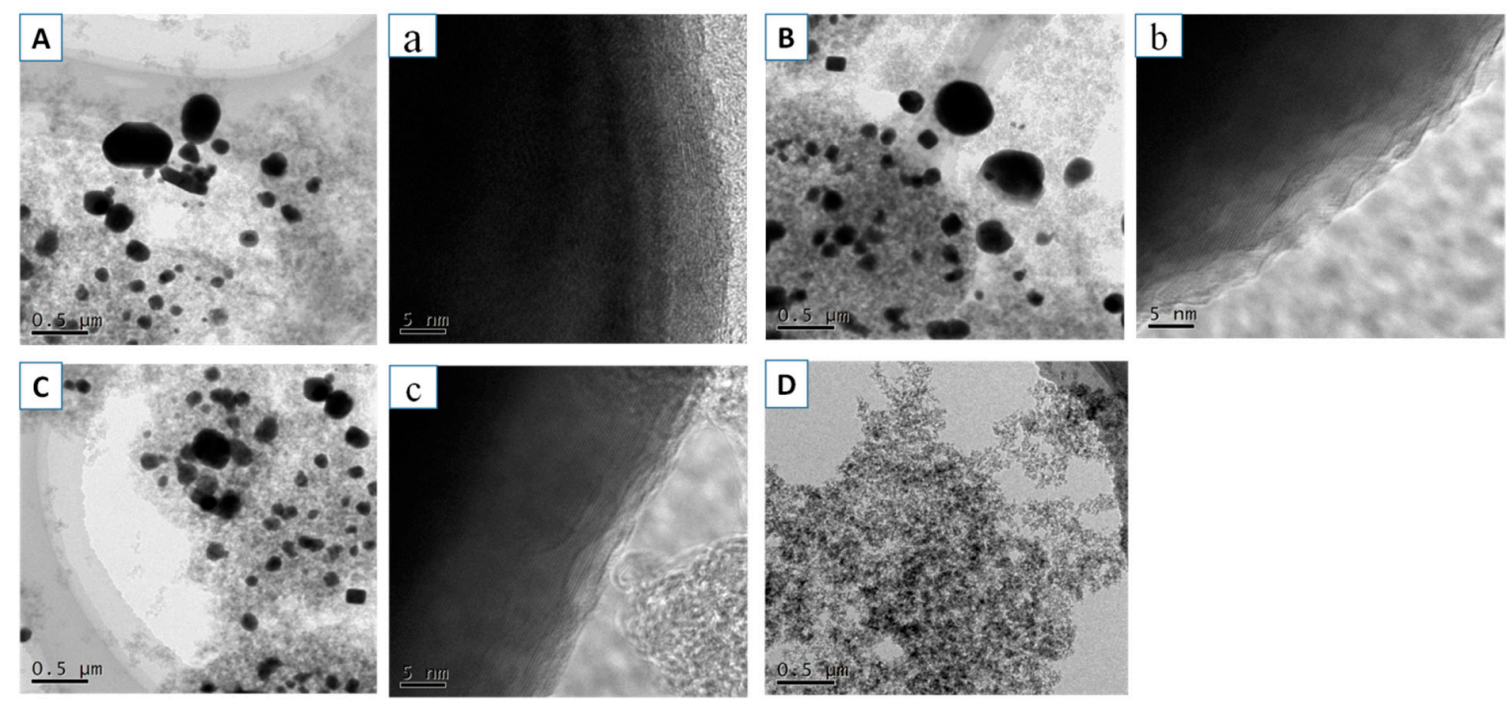

Figure 7. TEM images of (A) CA-Fe, (B) CA-Cr, (C) CA-Cu, and (D) Blank, HRTEM images of (a) $\mathrm{CA}-\mathrm{Fe},(\mathbf{b}) \mathrm{CA}-\mathrm{Cr}$ and (c) $\mathrm{CA}-\mathrm{Cu}$.

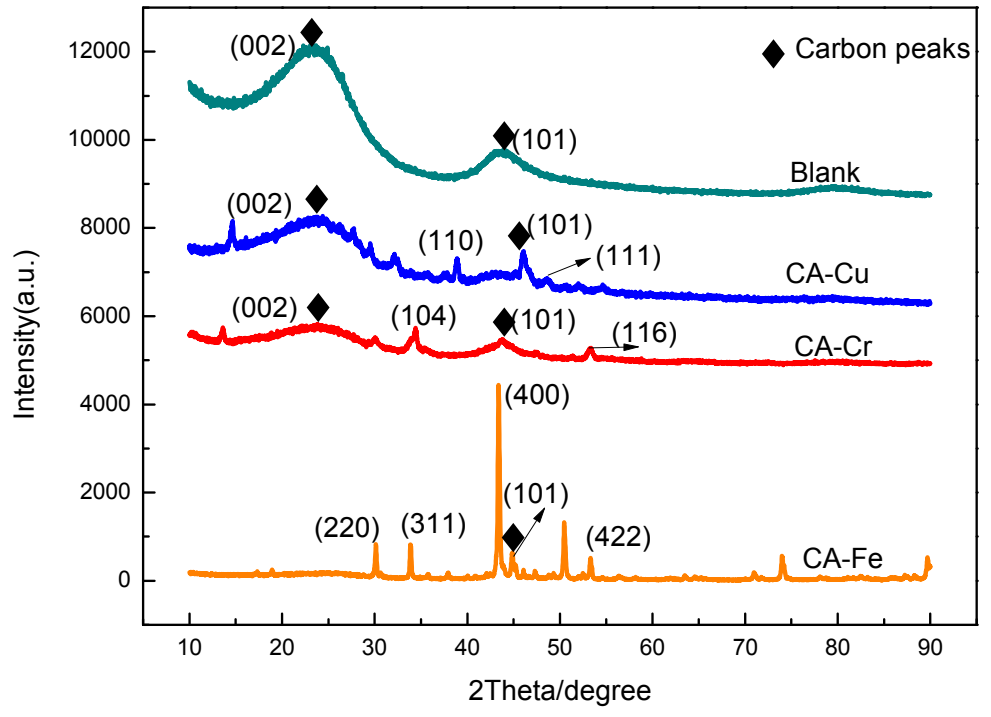

Figure 8. XRD patterns of CA-X.

\subsection{Electrochemical Performances of $C A-X$}

The electrochemical properties of $\mathrm{CA}-\mathrm{Fe}, \mathrm{CA}-\mathrm{Cr}, \mathrm{CA}-\mathrm{Cu}$, and the blank were investigated in a three-electrode system by using $6 \mathrm{M} \mathrm{KOH}$ aqueous as the electrolyte. The CV curves acquired at a scan rate of $0.5 \mathrm{mV} \cdot \mathrm{s}^{-1}$ were shown in Figure 10. The four kinds of samples showed sharp peaks indicative of the metals. The curve of the blank exhibited a rectangular-like shape, which showed the CAs had good electric double-layer capacitance behavior. In addition, this indicated that the samples had a nanostructure. CA-Fe had a subtle metal peak located at -0.514 and $-0.409 \mathrm{~V}$, which indicated that few iron ions were adsorbed and one peak at $-0.586 \mathrm{~V}$ together with another peak at $-0.454 \mathrm{~V}$ could be observed in the CV curve of CA-Cr while the peaks at -0.356 and $-0.254 \mathrm{~V}$ were assigned to CA-Cu, which is shown in Figure 10. All CV curves had two peaks, which implies the good faradaic pseudo capacitance nature [15]. The phenomenon demonstrated that Fe(III), $\mathrm{Cr}(\mathrm{VI})$, and $\mathrm{Cu}(\mathrm{II}) \mathrm{have}$ been successfully incorporated into CAs when compared with the blank. 

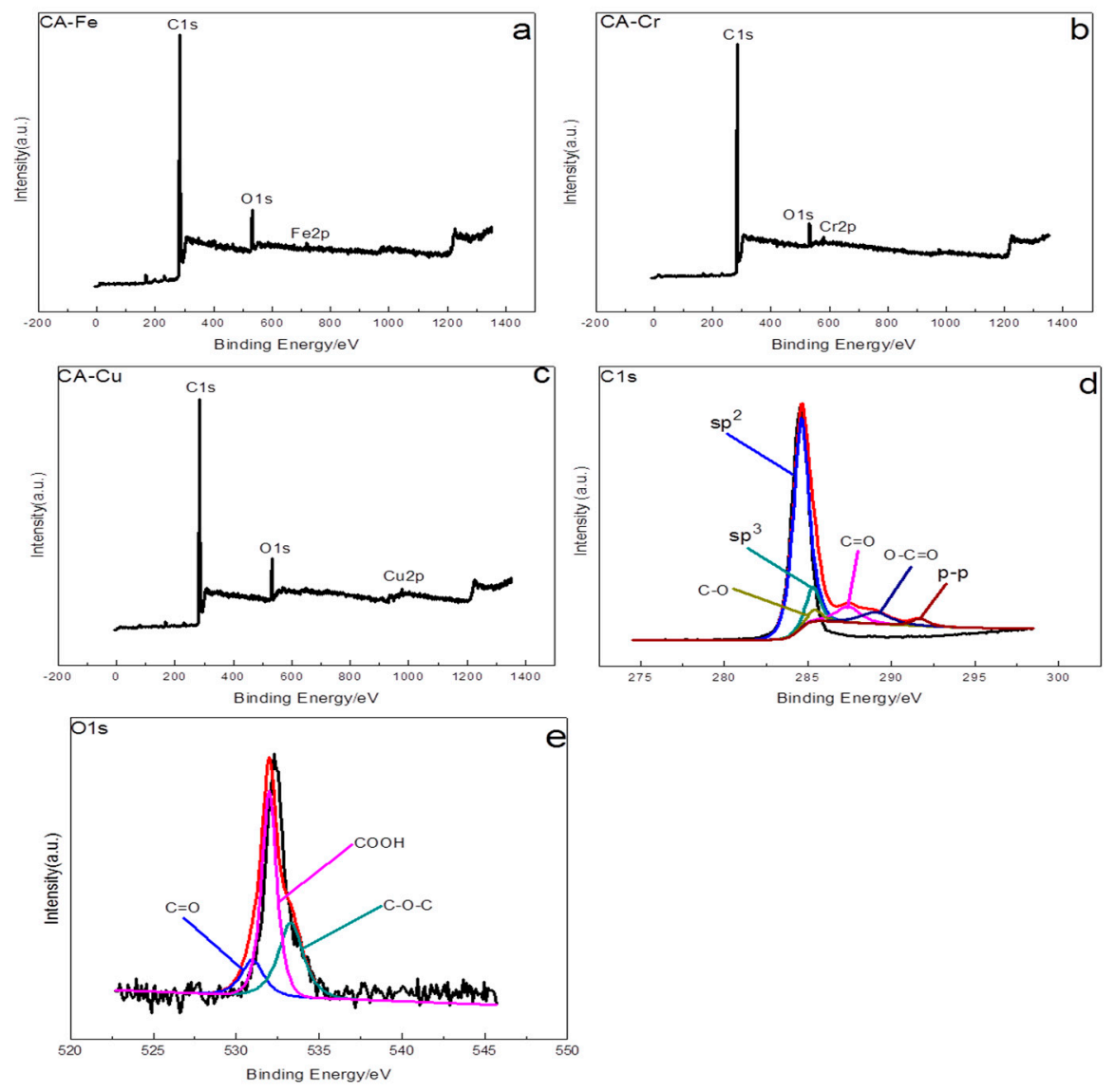

Figure 9. XPS spectra of $C A-X$, full-scan spectrum $(\mathbf{a}, \mathbf{b}, \mathbf{c}), \mathrm{C}_{1 \mathrm{~s}}(\mathbf{d})$, and $\mathrm{O}_{1 \mathrm{~s}}(\mathbf{e})$.

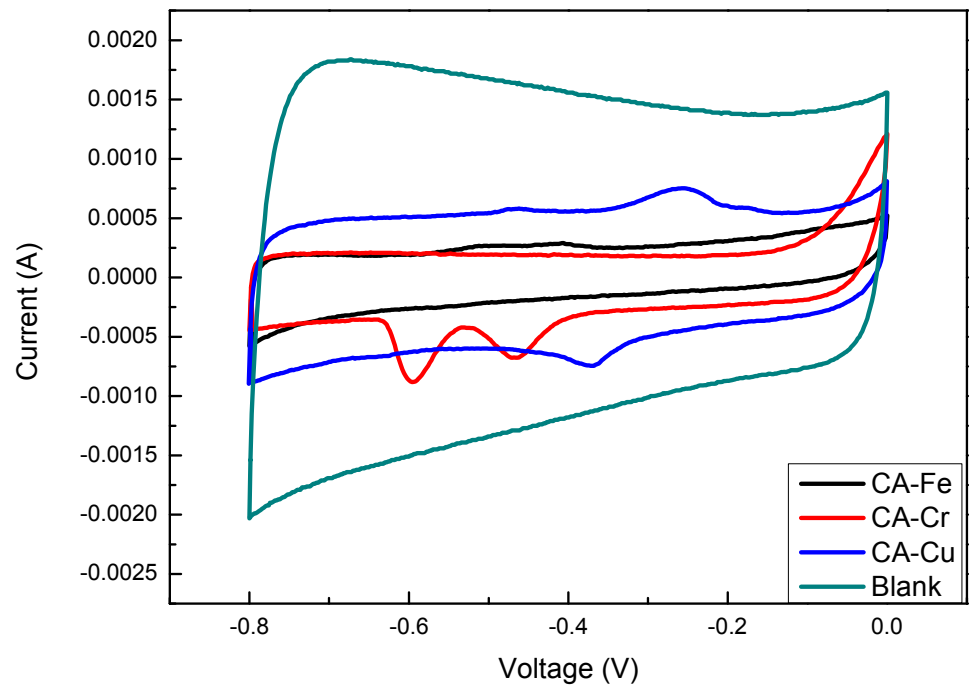

Figure 10. CV curves of different $\mathrm{CA}-\mathrm{X}$ at a scan rate of $0.5 \mathrm{mV} \cdot \mathrm{s}^{-1}$.

Figure 11 showed the galvanostatic charge-discharge measurements of $\mathrm{CA}-\mathrm{Fe}, \mathrm{CA}-\mathrm{Cr}, \mathrm{CA}-\mathrm{Cu}$, $\mathrm{CA}-\mathrm{Cu}-0$, and blank at a current density of $1.0 \mathrm{~A} \cdot \mathrm{g}^{-1}$. The curves were similar to isosceles triangles, which indicated that the charge-discharge had good symmetry and linearly increased or decreased over time. This shape also suggested that this material could serve as a reversible double layer capacitor. In addition, the ion hydration radius $\left(\gamma_{\mathrm{H}}\right)$ was related to the diffusion resistance. $\gamma_{\mathrm{H}}$ of $\mathrm{Cu}(\mathrm{II})$ was $4.19 \AA, \gamma_{\mathrm{H}}$ of $\mathrm{Cr}(\mathrm{VI})$ was $4.61 \AA$, and the $\gamma_{\mathrm{H}}$ of Fe(III) was $4.67 \AA[43,44]$. Clearly, the $\gamma_{\mathrm{H}}$ of $\mathrm{Cu}(\mathrm{II})$ was the smallest. Smaller $\gamma_{\mathrm{H}}$ values indicated lower diffusion resistance, which corresponded to 
improve charge transfer. The specific capacitance of the CA-Cu was $255 \mathrm{~F} \cdot \mathrm{g}^{-1}$, the blank was $125 \mathrm{~F} \cdot \mathrm{g}^{-1}$, and the CA-Fe was $215 \mathrm{~F} \cdot \mathrm{g}^{-1}$. The specific capacitance data were shown in Table 4 . This analysis result demonstrated that CAs not only removed metal ions but also the CAs adsorbing metals could be used as super capacitor materials. From Table 4, we discovered the specific capacitance of CA-Cu was $255 \mathrm{~F} \cdot \mathrm{g}^{-1}$, which was higher than that of CA-Cu-0. This result showed the copper ions of the CA-Cu-0 could desorb and come into the electrolyte. Table 5 showed the comparison of the super capacitors and similar materials.

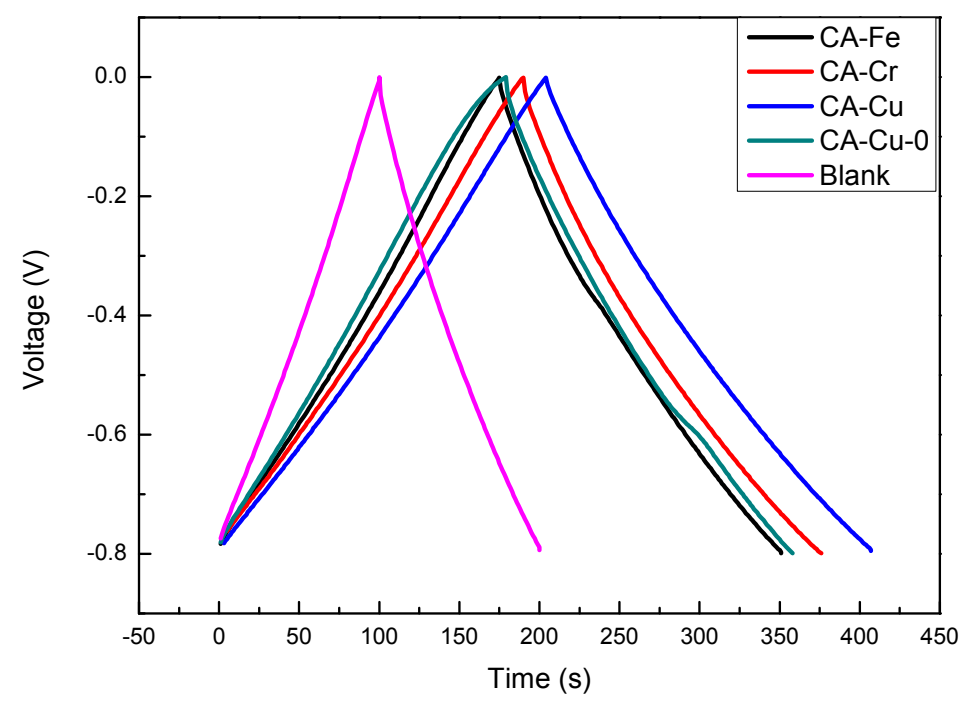

Figure 11. Galvanostatic charge-discharge curves at a current density of $1.0 \mathrm{~A} \cdot \mathrm{g}^{-1}$.

Table 4. The specific capacitance of CA-X and the blank at different current densities.

\begin{tabular}{|c|c|c|c|}
\hline \multirow{2}{*}{ Entry } & \multicolumn{3}{|c|}{ Specific Capacitance $\left(\mathrm{F} \cdot \mathrm{g}^{-1}\right)$} \\
\hline & $0.5 \mathrm{~A} \cdot \mathrm{g}^{-1}$ & $1.0 \mathrm{~A} \cdot \mathrm{g}^{-1}$ & $1.5 \mathrm{~A} \cdot \mathrm{g}^{-1}$ \\
\hline CA-Fe & 239 & 215 & 196 \\
\hline $\mathrm{CA}-\mathrm{Cr}$ & 256 & 238 & 213 \\
\hline $\mathrm{CA}-\mathrm{Cu}$ & 275 & 255 & 234 \\
\hline $\mathrm{CA}-\mathrm{Cu}-0$ & 250 & 224 & 186 \\
\hline Blank & 129 & 125 & 122 \\
\hline
\end{tabular}

Table 5. Comparison of the specific capacitance of different carbon materials.

\begin{tabular}{|c|c|c|c|c|}
\hline Carbon Species & Metal Species & Capacitance $\left(\mathrm{F} \cdot \mathrm{g}^{-1}\right)$ & Current Density $\left(A \cdot \mathrm{g}^{-1}\right)$ & Reference \\
\hline Carbon fiber & $\mathrm{V}$ & 104.05 & 0.5 & [15] \\
\hline Onion-like carbon & $\mathrm{Fe}$ & 251.2 & 0.5 & [45] \\
\hline Active carbon aerogels & Mn & 152 & 1.0 & [46] \\
\hline Carbon & $\mathrm{Ta}$ & 223 & 1.0 & [47] \\
\hline Graphene & $\mathrm{Zr}-\mathrm{MOFs}$ & 302 & 0.15 & [48] \\
\hline Carbon aerogel & $\mathrm{Cu}$ & 255 & 1.0 & This work \\
\hline
\end{tabular}

Figure 12 showed the durability and stability of CA-X, CA-Cu-0, and the blank. The samples were investigated by galvanostatic charge-discharge at a current density of $1.5 \mathrm{~A} \cdot \mathrm{g}^{-1}$. It revealed that the specific capacitance of CA-Cu still remained at $227 \mathrm{~F} \cdot \mathrm{g}^{-1}(\sim 97 \%)$ after 5000 charge-discharge cycles. Clearly, the CA-Cu displayed good cycling stability. Compared with CA-Cu-0, the CA-Cu had a better stability. At the same time, when compared with CA-Fe and CA-Cr, the better stability features of the CA-Cu might be the compact structures. 


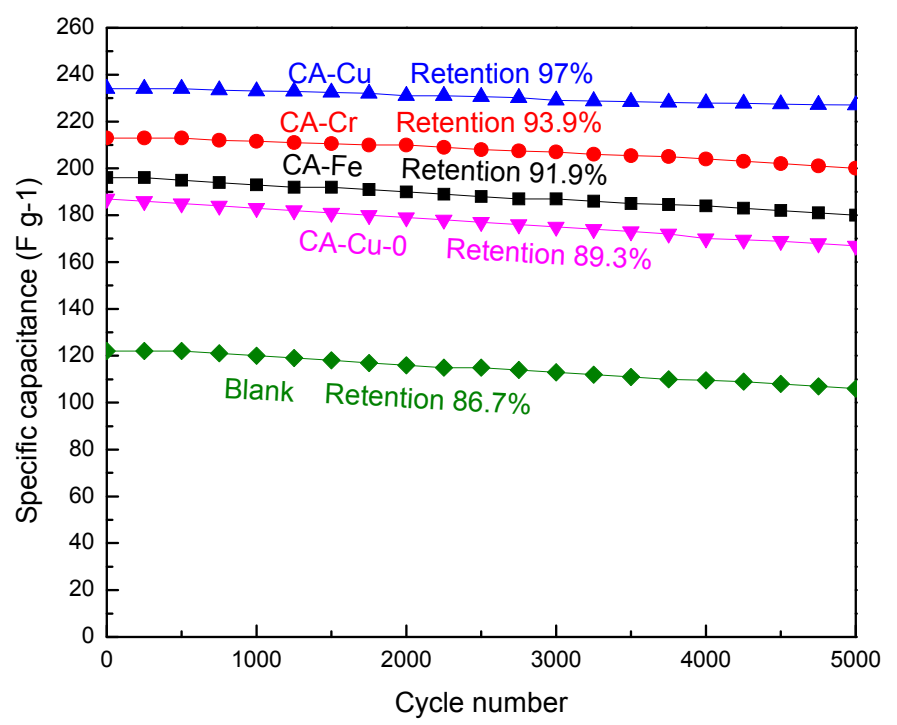

Figure 12. Charge/discharge cycles of CA-X, CA-Cu-0, and blank at the current density of $1.5 \mathrm{~A} \cdot \mathrm{g}^{-1 .}$

Figure 13 showed the EIS data including the resistance of CA-X and the blank. The frequency of the Nyquist plot ranged from 0.01 to $100 \mathrm{KHz}$. The plot was divided into two parts: one was the high frequency region, which was a semicircle [49], and the other was the low frequency region, which showed a similarly straight line. The semicircle represented the charge transfer resistance and a smaller radius indicated a smaller charge transfer resistance $\left(\mathrm{R}_{\mathrm{ct}}\right)$. The low frequency region reflected the ion diffusion rate, $R_{b}$ was the equivalent circuit resistance, $C_{d l}$ was the stationary phase element, $Z_{W}$ was the Warburg impedance, and $C_{L}$ was the intercalation capacitance. The electrode kinetics characterized the effect of metal adsorption on the pore structure. The EIS method evaluated the apparent chemical diffusion $\left(\mathrm{D}_{\mathrm{k}+}\right)$ of the blank and adsorbed metal into the CAs. The $\mathrm{K}^{+}$diffusion coefficient was expressed by the following formula [50].

$$
\begin{gathered}
Z_{r e}=\sigma \omega^{-1 / 2} \\
\Omega=2 \pi f \\
D_{k+}=\frac{R^{2} T^{2}}{2 A^{2} n^{4} F^{4} C^{2} \sigma^{2}}
\end{gathered}
$$

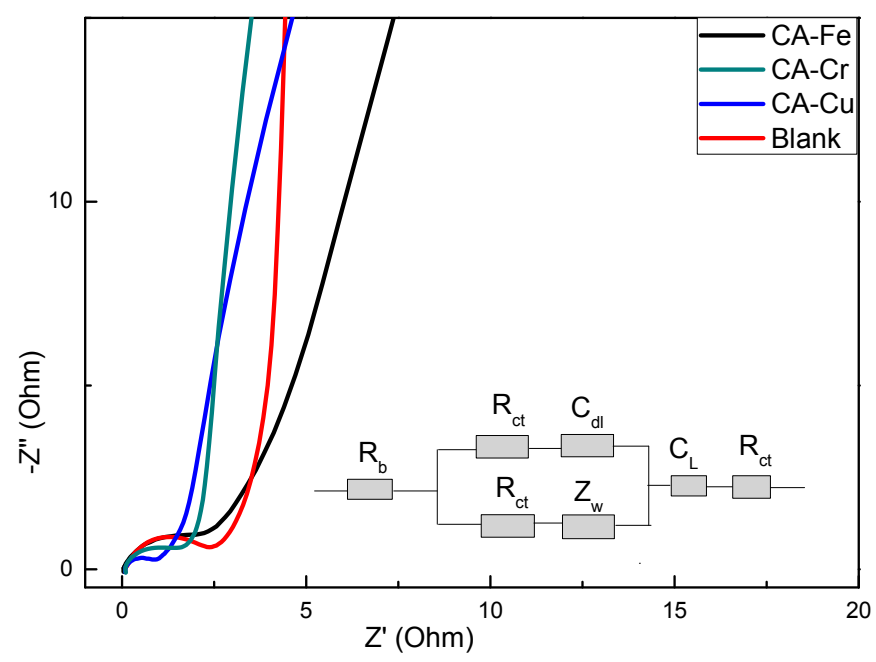

Figure 13. Nyquist plot of CA-X and the blank. 
In Formula (6), $\sigma$ is the slope of the line and $\omega$ is the angular frequency in the low frequency region. In Equation (7), $\mathrm{f}$ is the frequency. In addition, $\mathrm{A}$ is the specific area of the electrode $\left(0.785 \times 10^{-4} \mathrm{~m}^{2}\right), \mathrm{F}$ is the Faraday constant $\left(9.65 \times 10^{4} \mathrm{C} \cdot \mathrm{mol}^{-1}\right), \mathrm{n}$ represents the number of electrons per molecule involved in the electron transfer, $\mathrm{C}$ is the concentration of $\mathrm{K}^{+}$in the $\mathrm{KOH}$ solution $\left(6 \times 10^{3} \mathrm{~mol} \cdot \mathrm{m}^{3}\right), \mathrm{T}$ is the experimental temperature $(298 \mathrm{~K})$, and $\mathrm{R}$ is the gas constant $\left(8.314 \mathrm{~J} \cdot \mathrm{K}^{-1} \cdot \mathrm{mol}^{-1}\right)$. Figure 14 shows the slope. Combined with Equations (6-8), the $\mathrm{K}^{+}$diffusion coefficients in the CA-Fe, CA-Cr, CA-Cu and blank samples are $0.76 \times 10^{-15}, 1.8 \times 10^{-15}, 8.0 \times 10^{-15}$ and $0.5 \times 10^{-16} \mathrm{~cm}^{2} \cdot \mathrm{s}^{-1}$, respectively. It could be found that the $D_{k+}$ values of CA-X and blank are in the magnitude of $10^{-15} \mathrm{~cm}^{2} \cdot \mathrm{s}^{-1}$ and the diffusion coefficients of $\mathrm{K}^{+}$are increased when the $\mathrm{R}_{\mathrm{ct}}$ increases. This phenomenon revealed that the kinetics of $\mathrm{K}^{+}$and electro transfer into the electrodes were much faster at low $\mathrm{R}_{\mathrm{ct}}$. Among these samples, $\mathrm{K}^{+}$diffusion coefficients in the $\mathrm{CA}-\mathrm{Cu}$ was the biggest. Therefore, the charge transfer resistance of $\mathrm{CA}-\mathrm{Cu}$ was the smallest.

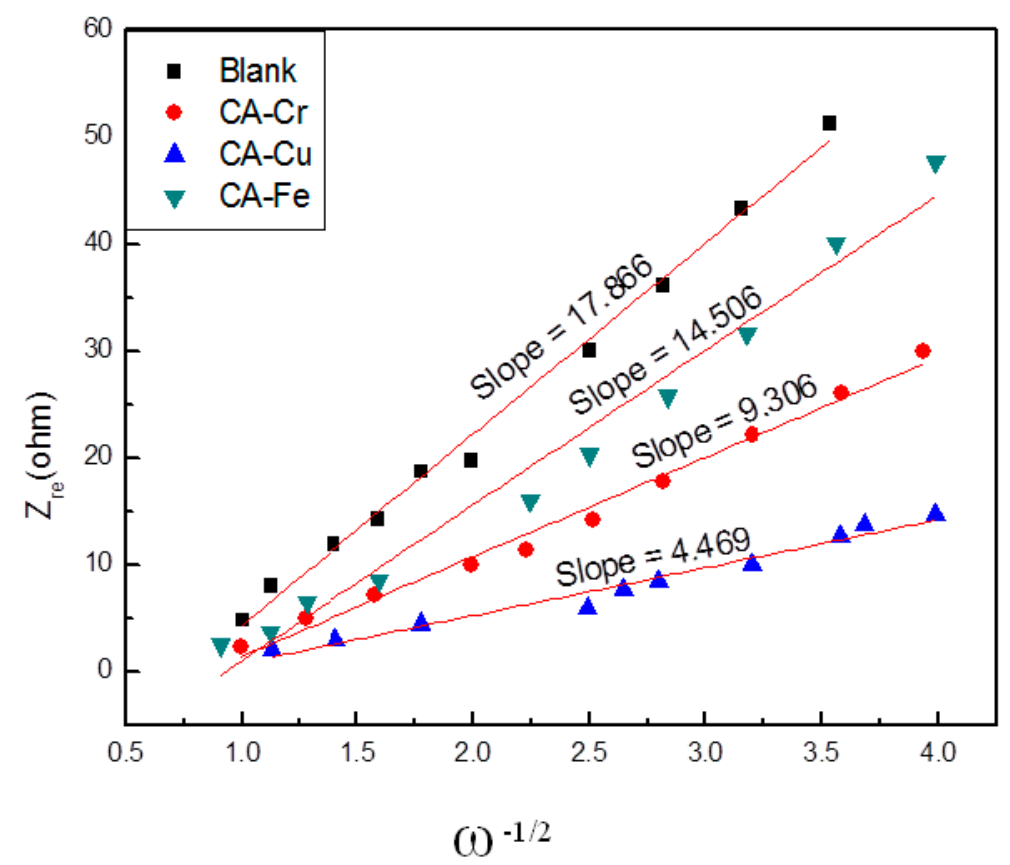

Figure 14. Nyquist graph of $Z_{\text {re }}$ plotted against $\omega^{-1 / 2}$ of CA-X and the blank.

\section{Conclusions}

In summary, CAs with a higher specific surface area were synthesized through the sol-gel process and the prepared materials exhibited an excellent adsorption capacity. At the same time, the metal ions adsorption on carbon aerogels executed a noticeable improvement for high super capacitor performance. In the adsorption tests, CAs demonstrated a high adsorption capacity for $\mathrm{Cu}$ (II), which could reach $424 \mathrm{mg} \cdot \mathrm{g}^{-1}$. The dynamics equation confirmed to the pseudo-second-order model and adsorption behavior could be described by the Langmuir adsorption isotherm equation, which indicated the adsorption process was single layer adsorption. The structure of CA-X could be more compact. In addition, metal-adsorbed carbon aerogel materials could be used as super capacitors. According to the results of electrochemical measurement, the electrochemical performance of $\mathrm{CAs}$ with adsorbed $\mathrm{Cu}$ (II) exhibited the highest specific capacitance, which reached $255 \mathrm{~F} \cdot \mathrm{g}^{-1}$ at $1.0 \mathrm{~A} \cdot \mathrm{g}^{-1}$. The excellent adsorption performance indicated that the carbon aerogel was a potential and effective absorbent for metal ions removal and the corresponding carbon aerogels could be used for super capacitors.

Author Contributions: Conceptualization, Methodology, Software, Validation, Formal Analysis, and Investigation, X.D. \& Y.X. Resources, L.Z. \& J.Z. Writing-Original Draft Preparation, X.D. Writing-Review \& Editing, Y.X., B.R., S.W., \& Z.L. Supervision, Z.L.; Project Administration, Y.X. \& Z.L. 
Acknowledgments: The Foundation of Key R \& D Program of Hebei Province (18393616D), science and technology projects of Hebei Academy of Sciences (18707), and the Natural Science Fund and Key Basic Research Project (18964005D) financially supported this work.

Conflicts of Interest: The authors declare no conflict of interest.

\section{References}

1. Ge, F.; Li, M.M.; Ye, H.; Zhao, B.X. Effective removal of heavy metal ions $\mathrm{Cd}^{2+}, \mathrm{Zn}^{2+}, \mathrm{Pb}^{2+}, \mathrm{Cu}^{2+}$ from aqueous solution by polymer-modified magnetic nanoparticles. J. Hazard. Mater. 2003, 99, 366-372. [CrossRef] [PubMed]

2. Wang, P.; Du, M.; Zhu, H.; Bao, S.; Yang, T.; Zou, M. Structure regulation of silica nanotubes and their adsorption behaviors for heavy metal ions: $\mathrm{pH}$ effect, kinetics, isotherms and mechanism. J. Hazard. Mater. 2015, 286, 533-544. [CrossRef] [PubMed]

3. Matlock, M.M.; Howerton, B.S.; Atwood, D.A. Chemical Precipitation of Lead from Lead Battery Recycling Plant Wastewater. Ind. Eng. Chem. Res. 2002, 41, 1579-1582. [CrossRef]

4. Fu, F.; Wang, Q. Removal of heavy metal ions from wastewaters: A review. J. Environ. Manag. 2011, 92, 407-418. [CrossRef] [PubMed]

5. Mohsen-Nia, M.; Montazeri, P.; Modarress, $\mathrm{H}$. Removal of $\mathrm{Cu}^{2+}$ and $\mathrm{Ni}^{2+}$, from wastewater with a chelating agent and reverse osmosis processes. Desalination 2007, 217, 276-281. [CrossRef]

6. Pekala, R.W.; Alviso, C.T.; Kong, F.M.; Hulsey, S.S. Aerogels derived from multifunctional organic monomers. J. Non-Cryst. Solids 1992, 145, 90-98. [CrossRef]

7. Sadasivam, S.; Krishna, S.K.; Ponnusamy, K.; Nagarajan, G.S.; Kang, T.W.; Venkatesalu, S.C. Equilibrium and Thermodynamic Studies on the Adsorption of an Organophosphorous Pesticide onto "Waste" Jute Fiber Carbon. J. Chem. Eng. Data 2010, 55, 5658-5662. [CrossRef]

8. Wu, M.; Jin, Y.; Zhao, G.; Li, M.; Li, D. Electrosorption-promoted Photodegradation of Opaque Wastewater on A Novel $\mathrm{TiO}_{2} /$ Carbon Aerogel Electrode. Environ. Sci. Technol. 2010, 44, 1780-1785. [CrossRef] [PubMed]

9. Kadirvelu, K.; Goel, J.; Rajagopal, C. Sorption of lead, mercury and cadmium ions in multi-component system using carbon aerogel as adsorbent. J. Hazard. Mater. 2008, 153, 502-507. [CrossRef] [PubMed]

10. Kabbashi, N.A.; Atieh, M.A.; Al-Mamun, A.; Mirghami, M.E.; Alam, M.D.Z.; Yahya, N. Kinetic adsorption of application of carbon nanotubes for $\mathrm{Pb}$ (II) removal from aqueous solution. J. Environ. Sci. 2009, 21, 539-544. [CrossRef]

11. Li, J.; Zheng, L.; Liu, H. A novel carbon aerogel prepared for adsorption of copper (II) ion in water. J. Porous Mater. 2017, 24, 1575-1580. [CrossRef]

12. Wang, H.; Zhou, A.; Peng, F.; Yu, H.; Yang, J. Mechanism study on adsorption of acidified multiwalled carbon nanotubes to $\mathrm{Pb}$ (II). J. Colloid Interface Sci. 2007, 316, 277-283. [CrossRef] [PubMed]

13. Snook, G.A.; Kao, P.; Best, A.S. Conducting-polymer-based supercapacitor devices and electrodes. J. Power Sources 2011, 196, 1-12. [CrossRef]

14. Yu, Z.; Tetard, L.; Zhai, L.; Thomas, J. Supercapacitor electrode materials: Nanostructures from 0 to 3 dimensions. Energy Environ. Sci. 2015, 8, 702-730. [CrossRef]

15. Wang, Y.; Jiang, M.; Yang, Y.; Ran, F. Hybrid Electrode Material of Vanadium Nitride and Carbon Fiber with Cigarette Butt/Metal Ions Wastes as the Precursor for Supercapacitors. Electrochim. Acta 2016, 222, 1914-1921. [CrossRef]

16. Hao, P.; Ma, X.; Xie, J.; Lei, F.; Li, L.; Zhu, W.; Cheng, X.; Cui, G.; Tang, B. Removal of toxic metal ions using chitosan coated carbon nanotube composites for supercapacitors. Sci. China Chem. 2018, 61, 797-805. [CrossRef]

17. Yu, D.; Wang, H.; Yang, J.; Niu, Z.; Lu, H.; Yang, Y.; Cheng, L.; Guo, L. Dye Wastewater Cleanup by Graphene Composite Paper for Tailorable Supercapacitors. ACS Appl. Mater. Interfaces 2017, 9, 21298-21306. [CrossRef] [PubMed]

18. Abdullah, N.; Rinaldi, A.; Hamid, S.B.A. Synthesis and Adsorption Performance of Carbon Materials for the Removal of Iron (III) from Aqueous Solution. ACS Appl. Mech. Mater. 2015, 699, 988-993. [CrossRef]

19. Zhao, Y.; Kunieda, M.; Obi, N.; Watanabe, S. Development of electrolyte filtration system for ECM taking into account removal of chromium (VI) ions. Precis. Eng. 2017, 49, 211-219. [CrossRef] 
20. Pang, J.S.; Deng, A.H.; Mao, L.B.; Chen, J.; Peng, X.J.; Zhu, J. Adsorption of Heavy Metal Ions with Magnetic Carbon-Coated Iron Nanoparitcles. Adv. Mater. Res. 2012, 490, 3049-3053. [CrossRef]

21. Yuan, X.; An, N.; Zhu, Z.; Sun, H.; Zheng, J.; Jia, M.; Lu, C.; Zhang, W.; Liu, N. Hierarchically porous nitrogen-doped carbon materials as efficient adsorbent for removal of heavy metal ions. J. Dairy Sci. 2018, 119, 320-329. [CrossRef]

22. Langmuir, I. The adsorption of gases on plane surfaces of glass, mica and platinum. J. Chem. Phys. 2015, 40, 1361-1403. [CrossRef]

23. Xu, Y.; Yan, M.; Wang, S.; Zhang, L.; Liu, H.; Liu, Z. Synthesis, characterization and electrochemical properties of carbon aerogels using different organic acids as polymerization catalysts. J. Porous Mater. 2017, 24, 1375-1381. [CrossRef]

24. Chen, J.P.; Wu, S.; Chong, K.H. Surface modification of a granular activated carbon by citric acid for enhancement of copper adsorption. Carbon 2003, 41, 1979-1986. [CrossRef]

25. Chen, J.P.; Wu, S. Acid/Base-treated activated carbons: Characterization of functional groups and metal adsorptive properties. Langmuir 2004, 20, 2233-2242. [CrossRef] [PubMed]

26. Ge, Y.; Li, Z.; Xiao, D.; Xiong, P.; Ye, N. Sulfonated multi-walled carbon nanotubes for the removal of copper (II) from aqueous solutions. J. Ind. Eng. Chem. 2014, 20, 1765-1771. [CrossRef]

27. Li, Y.; Liu, F.; Xia, B.; Du, Q.; Zhang, P.; Wang, D.; Wang, Z.; Xia, Y. Removal of copper from aqueous solution by carbon nanotube/calcium alginate composites. J. Hazard. Mater. 2010, 177, 876-880. [CrossRef] [PubMed]

28. Ademiluyi, F.T.; Ujile, A.A. Kinetics of Batch Adsorption of Iron II Ions from Aqueous Solution using Activated Carbon from Nigerian Bamboo. Int. J. Eng. Technol. 2013, 3, 623-631.

29. Huang, R.; He, L.; Zhang, T.; Li, D.; Tang, P.; Feng, Y. Novel Carbon Paper@Magnesium Silicate Composite Porous Films: Design, Fabrication, and Adsorption Behavior for Heavy Metal Ions in Aqueous Solution. ACS Appl. Mater. Interfaces 2018, 10, 22776-22785. [CrossRef] [PubMed]

30. Fan, L.; Luo, C.; Sun, M.; Qiu, H. Synthesis of graphene oxide decorated with magnetic cyclodextrin for fast chromium removal. J. Mater. Chem. 2012, 22, 24577-24583. [CrossRef]

31. Mishra, S.; Verma, N. Carbon bead-supported hollow carbon nanofibers synthesized via templating method for the removal of hexavalent chromium. J. Ind. Eng. Chem. 2016, 36, 346-354. [CrossRef]

32. Burwell, R.L. Manual of Symbols and Terminology for Physico-Chemical Quantities and Units-Appendix II, 1st ed.; Pergamon Press: Oxford, UK, 1981; pp. 285-286.

33. Chen, J.; Li, Y.; Ma, Y.; Qin, Y.; Chang, L. Formation of bamboo-shaped carbon filaments and dependence of their morphology on catalyst composition and reaction conditions. Carbon 2001, 39, 1467-1475. [CrossRef]

34. Haas, K.H. Hybrid Inorganic-Organic Polymers Based on Organically Modified Si-Alkoxides. Adv. Eng. Mater. 2010, 2, 571-582. [CrossRef]

35. Zhu, M.; Diao, G. Synthesis of Porous $\mathrm{Fe}_{3} \mathrm{O}_{4}$ Nanospheres and Its Application for the Catalytic Degradation of Xylenol Orange. J. Phys. Chem. C 2011, 115, 313-318. [CrossRef]

36. Hu, J.; Li, H.; Huang, X.; Chen, L. Improve the electrochemical performances of $\mathrm{Cr}_{2} \mathrm{O}_{3}$, anode for lithium ion batteries. Solid State Ion. 2006, 177, 2791-2799. [CrossRef]

37. Wang, C.; Fu, X.Q.; Xue, X.Y.; Wang, Y.G.; Wang, T.H. Surface accumulation conduction controlled sensing characteristic of p-type $\mathrm{CuO}$ nanorods induced by oxygen adsorption. Nanotechnology 2007, 18, 145506. [CrossRef]

38. El-Sheikh, S.M.; Rabah, M.A. Selective recovery of chromium ions from waste tannery solution for preparation of chromium oxide nanoparticles. Int. J. Environ. Sci. Technol. 2015, 12, 1-10. [CrossRef]

39. Li, L.; Yan, Z.F.; Lu, G.Q.; Zhu, Z.H. Synthesis and structure characterization of chromium oxide prepared by solid thermal decomposition reaction. J. Phys. Chem. B 2006, 110, 178-183. [CrossRef] [PubMed]

40. Zhu, H.; Sun, Z.; Chen, M.; Cao, H.; Li, K.; Cai, Y.; Wang, F. Highly porous composite based on tungsten carbide and $\mathrm{N}$-doped carbon aerogels for electrocatalyzing oxygen reduction reaction in acidic and alkaline media. Electrochim. Acta 2017, 236, 154-160. [CrossRef]

41. Zhang, J.; Zhang, L.; Yang, S.; Li, D.; Xie, Z.; Wang, B.; Xia, Y.; Quan, F. Facile strategy to produce N-doped carbon aerogels derived from seaweed for lithium-ion battery anode. J. Alloy. Compd. 2017, 701, 256-261. [CrossRef]

42. Fletcher, A.J.; Uygur, Y.; Thomas, K.M. Role of Surface Functional Groups in the Adsorption Kinetics of Water Vapor on Microporous Activated Carbons. J. Phys. Chem. C 2007, 111, 8349-8359. [CrossRef] 
43. Nightingale, E.R., Jr. Phenomenological Theory of Ion Solvation. Effective Radii of Hydrated Ions. J. Phys. Chem. 1959, 63, 1381-1387. [CrossRef]

44. Tansel, B.; Sager, J.; Rector, T.; Garland, J.; Strayer, R.F.; Levine, L.; Roberts, M.; Hummerick, M.; Bauer, J. Significance of hydrated radius and hydration shells on ionic permeability during nanofiltration in dead end and cross flow modes. Sep. Purif. Technol. 2006, 51, 40-47. [CrossRef]

45. Li, J.; Wang, N.; Deng, J.; Qian, W.; Chu, W. Flexible Metal-Templated Fabrication of Mesoporous Onion-Like Carbon and $\mathrm{Fe}_{2} \mathrm{O}_{3} @ \mathrm{~N}$-Doped Carbon Foam for Electrochemical Energy Storage. J. Mater. Chem. A 2018, 6, 13012-13020. [CrossRef]

46. Lee, Y.J.; Park, H.W.; Hong, U.G.; Song, I.K. Mn-doped activated carbon aerogel as electrode material for pseudo-capacitive supercapacitor: Effect of activation agent. Curr. Appl. Phys. 2012, 12, 1074-1080. [CrossRef]

47. Zhang, H.; Liu, J.; Tian, Z.; Ye, Y.; Cai, Y.; Liang, C.; Terabe, K. A general strategy toward transition metal carbide/carbon core/shell nanospheres and their application for supercapacitor electrode. Carbon 2016, 100, 590-599. [CrossRef]

48. Ke, Q.; Liao, Y.; Yao, S.; Song, L.; Xiong, X. A three-dimensional $\mathrm{TiO}_{2} /$ graphene porous composite with nano-carbon deposition for supercapacitor. J. Mater. Sci. 2016, 51, 2008-2016. [CrossRef]

49. Dong, B.; He, B.L.; Xu, C.L.; Li, H.L. Preparation and electrochemical characterization of polyaniline/multi-walled carbon nanotubes composites for supercapacitor. Mater. Sci. Eng. B 2007, 143, 7-13. [CrossRef]

50. Wu, D. Kinetic performance of $\mathrm{Li}_{4} \mathrm{Ti}_{5} \mathrm{O}_{12}$, anode material synthesized by the solid-state method. Ionics 2012, 18, 559-564. [CrossRef]

(C) 2018 by the authors. Licensee MDPI, Basel, Switzerland. This article is an open access article distributed under the terms and conditions of the Creative Commons Attribution (CC BY) license (http:/ / creativecommons.org/licenses/by/4.0/). 